\title{
Tubal Ligation
}

National Cancer Institute

\section{Source}

National Cancer Institute. Tubal Ligation. NCI Thesaurus. Code C92901.

A method of female sterilization where the fallopian tubes are surgically lig ated to prevent conception. 